

\title{
Returns to Education: Evidence from UK Twins*
}

\author{
Dorothe Bonjour \\ Policy Studies Institute \\ Lyn Cherkas \\ Twins Research and Genetic Epidemiology Unit, St. Thomas' Hospital \\ Jonathan Haskel \\ Queen Mary, University of London and CEPR \\ Denise Hawkes \\ Queen Mary, University of London \\ Tim Spector \\ Twins Research and Genetic Epidemiology Unit, St. Thomas' Hospital
}

January 2002

JEL Classification: I21, J24, J31

Keywords: Returns to education, ability bias, twins, measurement error, smoking

\begin{abstract}
We use a new sample of UK female identical twins to estimate private economic returns to education. We report findings in three areas. First, we use identical twins, to control for family effects and genetic ability bias, and the education reported by the other twin to control for schooling measurement error. Our estimates suggest a return to schooling for UK females of about $7.7 \%$. Second, we investigate within-twin pair ability differences by examining withintwin pair and between-family correlations of education with observable correlates of ability (including birthweight, ability tests and reading scores). Our findings suggest lower ability bias in within-twin pair regressions than pooled regressions. Third, using data on twins smoking we show smoking reflects family background and using it as an instrument exacerbates ability bias.
\end{abstract}

\footnotetext{
*Contact address: Jonathan Haskel, Economics, Queen Mary, University of London, London E1 4NS, England; j.e.haskel@qmul.ac.uk, <www.qmw.ac.uk/ ugte153>. We thank the DfEE and the ESRC (grant R00429924188) for financial support, Anna Vignoles for help with data and seminar participants at Warwick and Bergen for comments. The Labour Force Survey is Crown copyright. Errors are our own. This is a shorter version of a working paper of the same title which is available on the website above.
} 


\section{Introduction}

This paper attempts to estimate returns to education using a new data set of identical UK twins. ${ }^{1}$ We administered a questionnaire to around 6,600 individuals (3,300 same-sex twin pairs) in June 1999, all of whom are on the St. Thomas' UK Adult Twin Registry, based at the Twins Research and Genetic Epidemiology Unit, St. Thomas' Hospital, London, England. As well as the detailed medical information on the questionnaire, which covers age, birthweight, smoking etc., we asked the twins additional socio-economic questions on: earnings, occupation and schooling; test scores; and the schooling of the other twin. This paper reports results on 1,698 identical twins, of whom 428 comprise 214 identical twin pairs with complete wage and schooling information.

We believe our study is of interest for five main reasons. First, given the interest in genetics and economic success (see e.g. Herrnstein and Murray, 1994) data on genetically identical individuals are of particular value. $^{2}$ Second, there are comparatively few earnings/education studies based on identical twins (we are aware of seven). ${ }^{3}$ Thus we add to this literature. Third, our study is the first for the UK to present within-twin pair ${ }^{4}$ estimates using identical twins. Blanchflower and Elias (1999) used a sample of 23 twin pairs from the UK National Child Development Study, but there was insufficient variation of education within each twin pair to perform any within-pair regressions. Fourth, we have followed Ashenfelter and Krueger's (1994) innovation of asking one twin to report on the schooling of the other, in order to examine possible measurement error. Fifth, our study has more data on twins than other studies including test scores, reading scores and smoking behaviour.

The major criticism of within-twin pair estimates is set out by Bound and Solon (1999) and Neumark (1999), building on earlier work by Griliches (1979). They argue that whilst within-pair differencing removes genetic variation, differences might still reflect ability bias to the extent that ability is affected by more than just genes. To examine this, we follow and extend Ashenfelter and Rouse (1998). We calculate the correlation of average family education with those average family characteristics that might plausibly be

\footnotetext{
${ }^{1}$ Other returns to education methods that attempt to control for ability and background, use, for example IQ tests and detailed family background data sets (e.g. Deardon, 1999), or find an instrument, e.g. such as the raising of the school leaving age, proximity to college, or birth quarter, that is correlated with schooling but uncorrelated with earnings (see e.g. Harmon and Walker, 1998, Angrist and Krueger, 1991, Card, 1995). See Card (1999) for a survey.

${ }^{2}$ See e.g. Ashenfelter and Zimmerman (1997) for a study based on brothers and father - son pairs.

${ }^{3}$ The other economic studies are for the US, the Twinsburg sample (Ashenfelter and Krueger, 1994, Ashenfelter and Rouse, 1998, Rouse, 1999), the NAS study (Taubman, 1976) and the Minnesota studies (Behrman et al, 1999), for Sweden (Issacson, 1999) and for Australia (Miller et al, 1995).

${ }^{4}$ We follow the medical literature and use the term "within-twin pair", or "within pair" to describe estimates using differences between twins of the same pair. These are variously referred to in the economics literature as between-twins estimates, within-family estimates, first-difference estimates or within-twins estimates.
} 
correlated with ability or discount rates (e.g. birthweight, partner's characteristics and smoking). This indicates expected ability bias in a pooled regression. We then calculate the correlation of within-twin pair differences in education with within-twin pair differences in characteristics. This indicates expected ability bias in a within-twin pair regression. Using a range of variables, we find significant correlations in the pooled case, but no significant correlation in the within pair case. This suggests that ability bias in pooled regressions is likely to be higher than that using within pair regressions.

A new contribution of this paper is that we have data on twins' exam and reading scores. Like the other characteristics, we find no correlation between differences in these scores within-twin pairs and differences in their education. Finally, we also have data on smoking at 16 and 18 and we also investigate whether smoking is valid instrument for education. We find that smoking seems to be correlated with family background rather than reflecting individual discount rates and it is unlikely to be a valid education instrument. ${ }^{5}$

The plan of the rest of this paper is as follows. In the next section we set out some simple theory. In section 3 we describe the data and in Section 4 the results. Section 5 contains concluding remarks.

\section{Method}

Following Bound and Solon (1999), suppose the wage of twins 1 and 2 in family $f$ is determined by

$$
\begin{aligned}
& \log w_{1 f}=\beta S_{1 f}+A_{1 f}+\varepsilon_{1 f} \\
& \log w_{2 f}=\beta S_{2 f}+A_{2 f}+\varepsilon_{2 f}
\end{aligned}
$$

where $S_{i f}(i=1,2)$ is schooling, $A_{i f}$ is ability, broadly defined, i.e. all the other effects on wages outside those of schooling (intelligence, motivation, access to educational funds etc.) and $\varepsilon_{i f}$ is an iid error. ${ }^{6}$ Since $A_{i f}$ is typically poorly measured the usual estimate of (1) omits it (or includes some correlates that may not measure it fully) and estimates (1) pooling across individuals, returning an estimate of $\beta$ we denote $\beta_{\text {Pool. }}$. This gives rise to the standard omitted variable bias result from excluding $A_{i f}$

\footnotetext{
${ }^{5}$ We also discuss selection issues. Conventional estimates of female earnings equation focus a good deal on selection, but the issue for within pair estimates is whether selection affects not the sample level of education in but education differences.

${ }^{6} i$ takes the numbers 1 and 2 . We have one set of triplets on our data which we dropped.
} 


$$
\hat{\beta}_{P O O L}=\beta+\frac{\operatorname{cov}\left(S_{i f}, A_{i f}\right)}{\operatorname{var}\left(S_{i f}\right)}
$$

which simply says that if schooling and ability are positively correlated then $\beta_{P O O L}$ is upward biased. Assume now we can write $A_{i f}$ as

$$
A_{i f}=\alpha_{f}+g_{i f}+a_{i f}
$$

where $A_{i f}$ is composed of family effects (e.g. access to funds) denoted as $\alpha_{f}$, genetic effects (e.g. the part of intelligence due to genes), denoted $g_{i f}$ and the rest is captured by $a_{i f}$, which includes luck, optimisation error etc. Then the equations of twins 1 and 2 in family $f$ are given by

$$
\begin{aligned}
& \log w_{1 f}=\beta S_{1 f}+\alpha_{f}+g_{1 f}+a_{1 f}+\varepsilon_{1 f} \\
& \log w_{2 f}=\beta S_{2 f}+\alpha_{f}+g_{2 f}+a_{2 f}+\varepsilon_{2 f}
\end{aligned}
$$

A within-twin pair estimator for identical twins is based on differences within families of (5)

$$
\log w_{1 f}-\log w_{2 f}=\beta\left(S_{1 f}-S_{2 f}\right)+\left(a_{1 f}-a_{2 f}\right)+\left(\varepsilon_{1 f}-\varepsilon_{2 f}\right)
$$

where the family effect $\alpha_{f}$ and genetic effect $g_{i f}$ has been differenced out. Thus the basic idea of the withintwin pair method is to estimate returns to education controlling for the part of ability due to family background and genetic factors. The bias in this case is given by

$$
\hat{\beta}_{W T P}=\beta+\frac{\operatorname{cov}\left(S_{1 f}-S_{2 f}, a_{1 f}-a_{2 f}\right)}{\operatorname{var}\left(S_{1 f}-S_{2 f}\right)}
$$

There are two issues that arise. First, Rouse (1999) estimates that $10 \%$ of variation in schooling is due to measurement error. Since measurement error in schooling will be exacerbated by the differencing, estimates of (6) will be downward biased due to the attenuation bias arising from measurement error 
(Griliches, 1979, Neumark, 1999). We therefore follow Ashenfelter and Krueger (1994) in instrumenting the reported schooling differences with reported differences based on reports from the other twin. ${ }^{7}$

The second question is what causes the differences in schooling between identical twins? Ashenfelter and Rouse (1998), Bound and Solon (1999) and Neumark (1999, following earlier arguments due to Griliches, 1979) debate this at length in recent papers. As (2) shows, conventional OLS ability bias depends on the fraction of variance in schooling that is accounted for by variance in unobserved abilities that might also affect wages. Similarly, as (6) shows, within pair ability bias depends on the fraction of within pair variance in schooling that is accounted for by within pair variance in unobserved abilities that also affect wages. Thus if the endogenous variation within families is smaller than the endogenous variation between families, then $\beta_{\mathrm{WTP}}$ is less biased than $\beta_{\text {POOL }}$. Hence even if there is ability bias in within-twin pair regressions $\beta_{\mathrm{WTP}}$ might still be regarded as an upper bound on the returns to education (if schooling and ability are positively correlated). However, Bound and Solon (1999) argue there is no a priori reason to believe that $\beta_{\mathrm{WTP}}$ is less biased than $\beta_{\mathrm{POOL}}$.

Ultimately the matter is of course an empirical one. Its investigation is subject to the central problem that ability is not observed. Ashenfelter and Rouse (1998) therefore look at the correlation between schooling and potential correlates of ability (e.g. employment status, tenure and spouse's education). To investigate the covariance in (2) they examine the correlation between the average level of schooling and the average level of characteristics across different families. To investigate the covariance in (6) they examine the correlation between the difference in schooling and the differences in characteristics within families. They find the former is bigger than the latter and hence argue that most of the variation in ability is between families and not between twins within a family. We present some similar investigations below and find similar results to Ashenfelter and Rouse (1998). We also extend their results by looking at twins exam performance and literacy test scores.

Using the same framework we investigate the suggestion that smoking be used as an instrument for education, since it might proxy discount rates (Fuchs, 1982). Hamermesh (1999) suggested however that youth smoking is a measure of family background and thus not a valid instrument for education. We believe that our twins data allows us to shed some light on the smoking debate. Again, this is based on a comparison of correlations between and within families. A high correlation between family smoking behaviour and educational attainment is consistent with both views. However, significant within twin pair correlation is only

\footnotetext{
${ }^{7}$ Ashenfelter and Rouse (1998) and Rouse (1999) experiment with a number of different instrumentation methods using combinations of own and other twins reporting. Here we instrument using the report of one twin on the education of another. Other instrument configurations gave similar magnitudes to those reported below.
} 
consistent with the hypothesis that smoking reflects an individual's discount rate. Finding no within twin correlation provides indirect evidence for the family background view.

\section{Data}

\section{a. Data set}

The Twins Research Unit, St. Thomas' Hospital, London, has built up a list of (mainly female) identical and non-identical twins. The data we have used in this paper is derived from a mailing list to about 6,600 individuals. They are mailed questionnaires on mostly medical information (including birth weight, birth order, gestation period) plus socio-economic questions on sex, age, presence of children, age of mother etc. We added more detailed socio-economic questions to the most recent questionnaire which went out in June 1999. We asked the twins to report their qualifications, their twin's qualifications, the age they finished fulltime education, their occupation, their spouse's occupation, their employment status, earnings and household income (see Data Appendix for more details). We should note that response rates are very high (above 80\%) on these questionnaires, kept up by remailing and telephoning non-respondents.

Full details of our various measures are set out in the data appendix. To calculate wages we asked twins to report normal earnings before taxes and deductions and then asked whether this was hourly, daily, weekly, monthly or yearly. We also asked how many hours were usually worked (excluding meals and paid overtime). From these questions we converted the wage data into an hourly rate. To measure schooling, we asked each twin to report their qualification and their twin's qualification. Qualifications were split into 12 groups (e.g. University, A levels, 5+ O levels, 1-4 O levels etc. see data appendix). We then assigned years of education to each qualification. ${ }^{8}$

\section{b. Descriptive statistics and comparisons with other work}

We have 1,480 individual, identical twins, all of whom are women. Due to use of postal questionnaires, we do not necessarily have replies from both members of a twin pair. Of the identicals therefore we have 621 complete pairs i.e. 1,242 individuals. For 214 of these pairs (428 individuals) we have complete wage information on both twins in the pair. Thus our sample size is between the Ashenfelter and Krueger (1994, 298 individuals) and Ashenfelter and Rouse (1998, 680 individuals) and Rouse (1999, 906 individuals) studies. Our study is somewhat special as we only have data on female twins. Most of the other

\footnotetext{
${ }^{8}$ See Data Appendix. We refer to this education measure as "estimated" years of schooling. In our regressions we use estimated years. We tried different imputations for estimated years and found similar results Regressions with reported years gave similar coefficients but were less precisely determined (likely due to recall error).
} 
studies have both male and female twin pairs, although they do not attempt to estimate wage equations separately for men and women. Our sample size is less than Taubman (1976, 2,038 individuals), Behrman and Rosenweig (1999, 1,440 individuals), Miller et al (1995, 1,204 individuals) and Isacsson (1999, 4,984 individuals). However Taubman (1976) had no measurement error correction, Miller et al (1995) impute earnings from two-digit occupations and Behrman and Rosenzweig (1999) impute earnings for non-working women.

How does our data compare with Blanchflower and Elias (1999) (the only other UK twins study we are aware of)? They identify 267 (individual) twins from the National Child Development Study (a panel study of all UK births between $3^{\text {rd }}-9^{\text {th }}$ March 1958). This is a potentially very rich data set since it contains detailed information about, for example, test scores. There are however two difficulties with the study. First, due to high twin infant mortality and subsequent panel attrition, only 59 pairs have complete wage and education information and, of these, 23 pairs are classified as identical twins (see their figures 1 and 2). They therefore have too little variance among their 23 identical pairs to estimate within pair equations. Second, the twins were identified as identical at birth, but "... from the documentation we have available to us we are unclear how such designations were made in practice" (their footnote 6). The usual method at birth is to see if there were one or two placenta present and identify identicals as coming from one placenta. Unfortunately recent research indicates that as much as one third of identicals can come from double placentas (Bryan, 1992). Thus it seems likely that their sample of identicals is identified with substantial error. ${ }^{9}$

An important innovation of the Ashenfelter and Krueger (1994) study is to ask each twin his/her own and their cotwin's education. If self-reported education is measured with error this provides a potential instrument since the report of the other twin should be correlated with the self-reported education level but uncorrelated with the equation regressand. This strategy was adopted in the subsequent Twinsburg studies, the Miller et al (1995) study and ours. Isacsson (1999) uses the comparison of reported education and registry information to control for measurement error.

Table 1 sets out some descriptive statistics for our data along with comparative data from the Labour Force Survey (LFS) as a check on the representativeness of our sample. Column 1 shows data from the 1999 LFS for all women and all women who report a wage. These women average 12.1 years of schooling, are aged 39 and 59.5\% are married. Column 3 sets out data for all identical twins. They have 12.6 years of schooling, are aged 44.3 and $65.1 \%$ are married. So our twins are slightly more educated and slightly older, but our data do not seem to be too far from the average for women. Column 4 shows the data for our working 
twins, who earn, on average, $£ 10.17$ per hour, have worked in the present job for 11.7 years and $58.2 \%$ are part time. Comparing this to column 2, which shows the LFS data for working women, wages and tenure are slightly lower. These lower LFS figures presumably reflect the somewhat more educated twins sample. The figures are very similar if we only consider twin pairs (columns 5 and 6).

\section{Results}

\section{a. Returns to Education}

Table 2 sets out our estimates. Column 1 shows an OLS regression using all working women from the LFS, entering schooling, age and age squared. The return to education is quite precisely estimated at $7.8 \%$. The rest of the columns are estimates for twins. Column 2 is an OLS pooled regression of (1) using all identicals for whom we have complete wage information, 428 individuals, and schooling, age and age squared as regressors. This gives a return to education of $7.7 \%$, similar to figure in column 1. Dearden's (1998) equivalent results on the NCDS are about $12.2 \%$ (see her table 4.3, column 1, no control for ability or family background). Column 3 maintains a pooled specification, but instruments education with reported level of the other twin. This should control for measurement error in reported education which would bias down the returns estimate. As column 3 shows, returns rise to $8.5 \%$ when this is done.

Column 4 estimates the within pair equation (5). Figure 1 illustrates data in this case. The cluster around zero is due to the fact that $55 \%$ of the twin pairs have the same education years. Since the pooled estimates do not control for ability bias we would expect the within pair returns estimates to be less. ${ }^{10}$ As column 4 of Table 5 shows, the return is indeed less, at 3.9\%, but is poorly determined. This figure might however reflect downward bias due to exacerbated measurement error in the differenced equation. To check this column 5 instruments reported schooling. As expected the point estimate rises to $7.7 \%$, with a standard error of 0.033. Comparison of the pooled IV and the first difference IV estimates therefore provide an estimate of the magnitude of ability bias as both control for measurement error; comparing columns 3 and 5 suggests ability bias is positive.

The right hand panel of the table repeats the exercise controlling for marriage, current job tenure and part-time status. Interestingly, the pattern of estimates on the regressors is exactly the same. The pooled OLS estimates $(7.2 \%)$ are lower than the pooled IV estimates $(7.9 \%)$ that control for measurement error. The

\footnotetext{
${ }^{9}$ Note in passing they also find the sample of identicals have no significant within-twin pair differences for maths and reading scores, see their Table 8 .

${ }^{10}$ If the variation within-twin pairs is uncorrelated with ability, or if there is more between family ability bias than within-family bias.
} 
within pair estimate $(3.8 \%)$ is less than the pooled estimate, whilst the within pair estimate controlling for measurement error $(7.9 \%)$ is more than the simple within pair estimate.

Thus we can conclude the following. First, ability bias appears to bias the pooled estimates upwards. Second, measurement error appears to bias all estimates downwards especially in the case of the within pair estimate. Third, female returns to education appear to be about 7.7\%. Fourth, Dearden (1998) obtains returns of $8.3 \%$ for women after controlling for ability and family background (see her Table 4.3, column 4). Thus our results are similar to hers.

\section{b. Ability differences within twin pairs}

To investigate ability biases within and between families Table 3 shows the results of the correlation analyses. Consider the first column, first row. This shows that the correlation between average family education and average family birthweight is 0.22 and is highly significant. It suggests that families with low average birthweight have low average schooling, consistent with ability and family background affecting schooling choice. The second column shows an insignificant correlation between differences in education within-twin pairs and differences in birthweight within-twin pairs. To the extent that birthweight measures ability therefore, between family differences in education are more affected by ability bias than the within pair education differences.

The rest of the first column shows other family correlations.. This shows strong correlations between average family education and average family marriage status, self-employment, part-time status, partner's tenure and partner's occupation. The second column shows the correlations between within pair differences in education and within pair differences in characteristics. None of them are significant. In sum, within pair education differences are uncorrelated with any other within-twin difference in observables. Of course, these characteristics are incomplete measures of ability, but the evidence is suggestive, especially as it mirrors that found by the Ashenfelter and Rouse (1998).

For a sub-sample of twins we managed to collect more detailed data on characteristics that are also likely to be highly correlated with ability. For these twins we have their reading score on the National Adult Reading Test (NART) and whether the twins passed the 11+ exam (an exam taken at age 11). Before the introduction of comprehensive schools, the 11+ was universally applied across Britain as a means of selecting which secondary school to attend. If the pupil passed the $11+$ (around $25 \%$ of the population) this meant that they were selected to attend a Grammar school where education was largely academically based. If the pupil did not pass they were selected to attend a Secondary Modern school where education was more vocationally based. As a result this $11+$ test result can be regarded as an early ability test. However, we only have data on 
48 pairs (96 individuals) who reported the answer to this question in a short follow-up questionnaire we conducted. Of these 48 pairs only 3 pairs actually received a different result in the $11+$ test. As shown in the lower panel of Table 6, correlations between families and within twins show a pattern similar to upper panel.

In addition to this early ability measure an adult ability measure is also available for a subset of twins. The measure is the National Adult Reading Test (NART) which is based on the ability to read and correctly pronounce each word from a list of 25 words. Of course, being an adult reading test, the result may be affected by the schooling the respondent has received. However, Crawford et al (2001) compared NART results of 77 year olds with IQ tests taken when the same individuals were 11 and obtained a correlation of 0.69. We have NART test results for 108 identical twin pairs (the twins' scores had a correlation of 0.71 ). As shown in Table 3, the NART results confirm the same pattern as the other ability correlates: there is a high and significant correlation between average family NART and average family education but the corresponding correlation of within-twin differences is insignificant. This is additional evidence that educational differences within twin pairs are likely be less correlated with ability difference than across families.

\section{c. Smoking as an instrument?}

A strength of our data is that we have information on the smoking behaviour of the twins at the age of 16 and 18. Smoking has been suggested as an instrument for education, since it might proxy discount rates (Fuchs, 1982) and subsequently been used by Evans and Montgomery (1994) for the US and Chevalier and Walker (1999) for the UK. This was criticised by Hamermesh (1999) who suggests that a youth's smoking behaviour is a measure of family background and thus not a valid instrument for education.

Evans and Montgomery (1994) show that smoking is highly correlated with educational outcomes and use it as an instrument in estimating returns to education. Their IV estimate of the returns to education lies about 10 per cent above the OLS estimate ${ }^{11}$. This would indicate negative ability bias, unlike twins studies where ability bias is small or positive. Evans and Montgomery present indirect evidence that the correlation of smoking and educational attainment is due to differences in time preferences. However, they acknowledge that there is no possibility to test this directly against the alternative hypothesis that the observed correlation is due to unobserved 'ability' in a very broad sense including genes, family and social background as well as peers.

\footnotetext{
${ }^{11}$ The difference is higher in their estimates for females only.
} 
While not able to perform a direct test, our twin data allow us to give additional - and in our view more compelling - indirect evidence which relies on the correlation method in Table 3. A significant negative correlation between average family smoking and average family education is consistent with either smoking reflecting discount rates or family background. However, if smoking affects individual's discount rates differences in smoking within families should be correlated with differences in education. But the within pair correlation should be insignificant if the cross-sectional correlation between smoking and education is due to family background.

Table 4 shows the correlation results for smoking. There is a significant negative correlation between average family smoking and family education. However, there is no significant correlation between withintwin pair smoking and within-twin pair education. This suggest smoking is more likely to reflect family background than discount rates.

Furthermore, if the family background view is true and if ability bias is positive - as is the case for our data - then using smoking as an instrument is likely to exacerbate ability bias. Table 5 investigates this. Column 1 upper panel shows, for comparison, the pooled OLS results from column 2 of Table 3 . The return of 0.077 compares closely with two smoking studies in the literature set out in the lower panel, Evans and Montgomery (1994, 0.079) and Chevalier and Walker (1999, 0.099). The second and third columns shows returns to education when using smoking at 16 and 18 as an instrument. The returns rise just as in the Chevalier/Walker and Evans/Montgomery studies (see lower panel), consistent with an exacerbation of positive ability bias. The final column investigates smoking at 18 and finds a similar effect. In sum, evidence seems to suggest that smoking reflects family background rather than discount rates. Thus the higher estimated returns in studies using smoking as an instrument are more likely caused by an augmentation of (positive) ability bias than the existence of negative ability bias.

\section{d. Selection bias}

How are the returns to education estimates affected by possible selection bias? There are several selection processes going on. Here we will focus on two: taking part in the study (volunteering to be on the data base and returning the specific questionnaire) and participating in the labour market. They might affect pooled estimations differently form within-twin pair estimations.

Consider first the effects on the pooled estimates. Selection into the study arises since twins have to volunteer to be on the database and return the questionnaire. Better educated twins seem more likely to do this as they are more likely to be in our sample (see Table 2). However, if returns to education are linear in schooling, then having a sample of highly schooled individuals should not matter. If returns are non-linear 
but characterised by diminishing marginal returns ${ }^{12}$ then, since we have a slightly above average education group, our pooled estimates would understate average marginal returns. As in all studies that are concerned with wages there is the potential of selection bias due to the participation decision. As our sample consists of female twins selection issues of this kind do potentially affect our estimates. We therefore experimented with traditional Heckman-correction models (using children and husband's occupation in the selection equation) but found no evidence that selection affected our estimates significantly.

Our main estimates are however of within-twin pair differences. The key point with respect to selection is that we are not concerned with whether the average characteristics of the group are nonrepresentative, but whether differences in education within twin pairs are non-representative of differences in education in general. The two main selection issues discussed above could also affect the differences. First, both twins need to respond to the questionnaire, and second, both twins have to be working. It is not straightforward to show how these selection processes affect differences within-twin pairs and which way potential biases would go.

\section{Conclusions}

We have used a new sample of UK twins to estimate returns to education using the within-twin pair method allowing for measurement error. Our findings suggest a number of key results. Firstly, our twin estimates confirm the theoretical prediction that measurement error biases estimated returns to education up and omitting ability biases estimates down. These effects roughly cancel each other out indicating a private return to education for women of $7.7 \%$. Second, we find no evidence that ability bias affects our within-twin pair estimator by more than the between family estimator. Thus we expect ability biases to be less for within pair estimators than for estimators not controlling for ability. Therefore our estimates at least tighten the upper bound for the returns to education.

Third, we present evidence that smoking behaviour used in the literature as an instrument for education is more likely to reflect family background than the assumed discount rates. Therefore, smoking behaviour should not be used as an instrument for education as it is likely to exacerbate ability bias.

In future work we hope to be able to extend the data set to consider male twins and, with an increased sample size consider the issue of heterogeneous returns to education both with respect to different qualifications and to parental background.

\footnotetext{
${ }^{12}$ The higher marginal returns in IV studies are often attributed to high marginal returns for a low educated group whose behaviour is frequently the source of variation of the instrument (Card, 1999).
} 
Table 1

Descriptive statistics

\begin{tabular}{|c|c|c|c|c|c|c|}
\hline & \multicolumn{2}{|c|}{ LFS 1999} & \multicolumn{2}{|c|}{ Identical Twins } & \multicolumn{2}{|c|}{ Identical Twin Pairs } \\
\hline & $\begin{array}{l}\text { All } \\
(1)\end{array}$ & $\begin{array}{c}\text { Working } \\
(2)\end{array}$ & $\begin{array}{l}\text { All } \\
(3)\end{array}$ & $\begin{array}{c}\text { Working } \\
(4)\end{array}$ & $\begin{array}{l}\text { All } \\
(5)\end{array}$ & $\begin{array}{c}\text { Both Work } \\
\text { (6) }\end{array}$ \\
\hline $\begin{array}{l}\text { Reported Years of } \\
\text { Schooling a) }\end{array}$ & $\begin{array}{l}12.1 \\
(2.37)\end{array}$ & $\begin{array}{l}12.3 \\
(2.39)\end{array}$ & $\begin{array}{l}12.6 \\
(2.89)\end{array}$ & $\begin{array}{c}13.0 \\
(2.92)\end{array}$ & $\begin{array}{l}12.6 \\
(2.89)\end{array}$ & $\begin{array}{c}13.2 \\
(3.04)\end{array}$ \\
\hline $\begin{array}{l}\text { Estimated Years of } \\
\text { Schooling }{ }^{\text {) }}\end{array}$ & $\begin{array}{l}12.5 \\
(2.32)\end{array}$ & $\begin{array}{l}12.9 \\
(2.35)\end{array}$ & $\begin{array}{l}13.5 \\
(2.52)\end{array}$ & $\begin{array}{l}13.9 \\
(2.48)\end{array}$ & $\begin{array}{l}13.5 \\
(2.54)\end{array}$ & $\begin{array}{l}14.1 \\
(2.50)\end{array}$ \\
\hline Age & $\begin{array}{c}38.9 \\
(11.08)\end{array}$ & $\begin{array}{c}38.6 \\
(10.72)\end{array}$ & $\begin{array}{c}44.3 \\
(10.40)\end{array}$ & $\begin{array}{c}42.7 \\
(10.15)\end{array}$ & $\begin{array}{c}44.8 \\
(10.3)\end{array}$ & $\begin{array}{c}42.5 \\
(10.0)\end{array}$ \\
\hline Married (\%) & 59.5 & 60.3 & 65.1 & 61.4 & 65.3 & 61.3 \\
\hline White (\%) & 94.9 & 96.6 & 98.3 & 98.4 & 98.6 & 98.3 \\
\hline $\begin{array}{l}\text { Non }(\%) \\
\text { Participation }\end{array}$ & 29.0 & 0 & 18.2 & 0 & 18.6 & 0 \\
\hline Hourly Wage Rate & & $\begin{array}{c}7.09 \\
(4.37)\end{array}$ & & $\begin{array}{c}10.17 \\
(10.36)\end{array}$ & & $\begin{array}{l}10.03 \\
(9.12)\end{array}$ \\
\hline Tenure & & $\begin{array}{c}6.9 \\
(6.84)\end{array}$ & & $\begin{array}{l}11.7 \\
(9.64)\end{array}$ & & $\begin{array}{l}11.9 \\
(9.15)\end{array}$ \\
\hline Full Time (\%) & & 58.5 & & 58.2 & & 60.8 \\
\hline Self Employed (\%) & & 4.8 & & 5.1 & & 4.9 \\
\hline $\begin{array}{l}\text { Sample Size } \\
\text { (Individuals) }\end{array}$ & 7729 & 4226 & 1364 & 748 & 1242 & 428 \\
\hline
\end{tabular}

Notes: Standard deviations in parentheses; ${ }^{\text {a) }}$ Based on age when finished fulltime education minus five; ${ }^{\text {b) }}$ Based on highest qualification (see data appendix); 


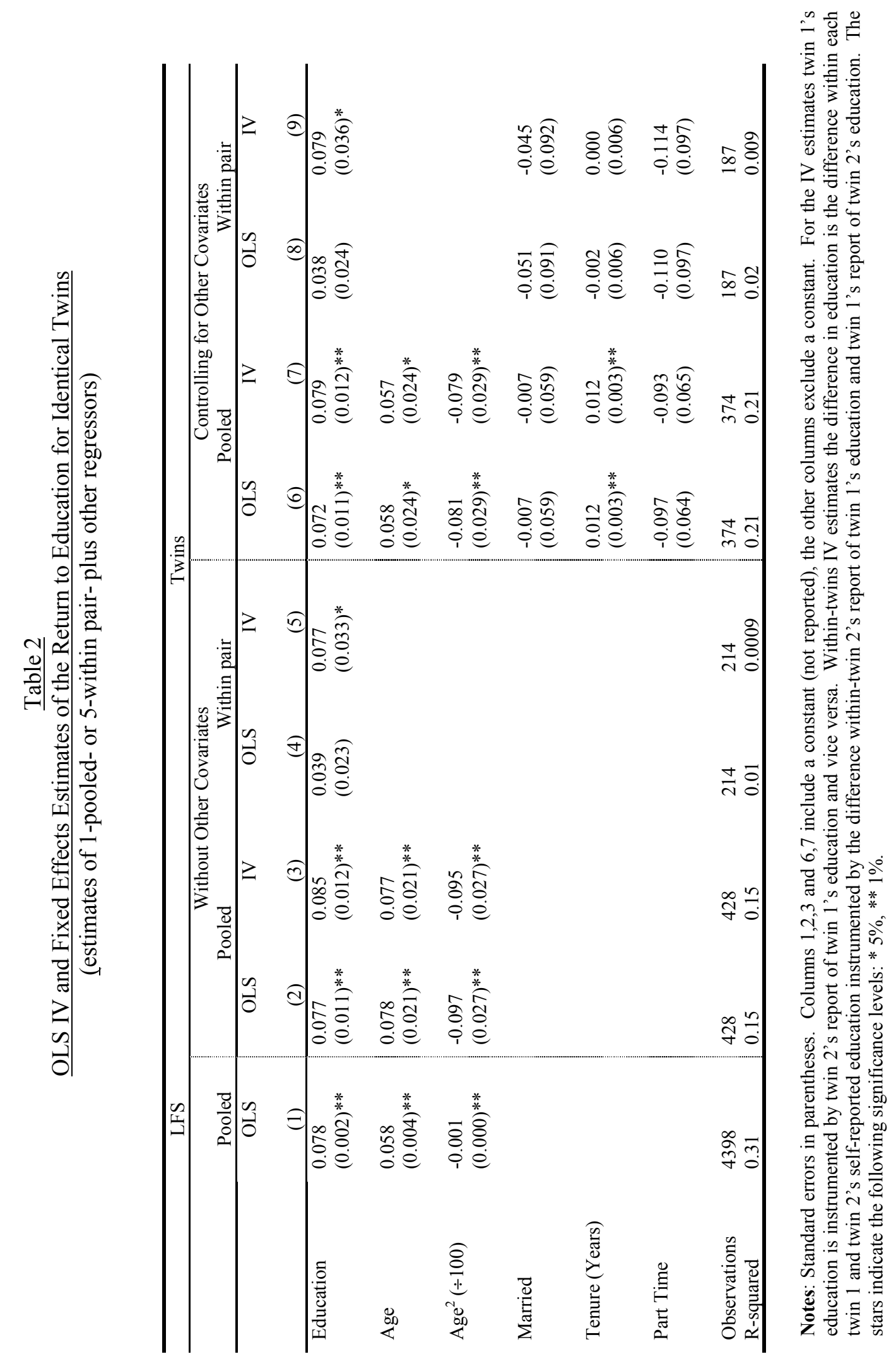


Table 3

Between family and within family twin pair correlation

\begin{tabular}{llll}
\hline $\begin{array}{l}\text { Correlation of average family education } \\
\text { with average family characteristics }\end{array}$ & \multicolumn{2}{l}{$\begin{array}{l}\text { Correlation of within-twins differences in education } \\
\text { with within-twins difference in other characteristics }\end{array}$} \\
\hline & Education & & $\Delta$ Education \\
\hline Birthweight & $0.2153^{* * *}$ & $\Delta$ Birthweight & -0.0765 \\
Married & $-0.1279^{* * *}$ & $\Delta$ Married & -0.031 \\
Self Employed & $-0.0876^{*}$ & $\Delta$ Self Employed & -0.03 \\
Part Time & $-0.2067^{* * *}$ & $\Delta$ Part Time & 0.0379 \\
Partner's Tenure & $-0.2124^{* * *}$ & $\Delta$ Partner's Tenure & -0.0093 \\
Partner's Occupation & $0.4908^{* * *}$ & $\Delta$ Partner's Occupation & 0.0305 \\
\hline For reduced sample: & & & -0.0556 \\
\hline Passing 11+ & 0.1095 & $\Delta$ Passing 11+ \\
Adult Reading Score ${ }^{\text {a) }}$ & $0.4933^{* * *}$ & $\Delta$ Adult Reading Score & 0.2111 \\
\hline
\end{tabular}

Note: stars indicate the following significance levels: $* 10 \%, * * 5 \%, * * * 1 \%$. ${ }^{\text {a) }}$ The reading score used is the National Adult Reading Test (NART).

Table 4

Between family and within family twin pair correlation of education and smoking

\begin{tabular}{llll}
\hline $\begin{array}{l}\text { Correlation of average family education } \\
\text { with average family characteristics }\end{array}$ & \multicolumn{2}{l}{$\begin{array}{l}\text { Correlation of within-twins differences in education } \\
\text { with within-twins difference in other characteristics }\end{array}$} \\
\hline & Education & & $\Delta$ Education \\
\hline Smoking at 16 & $-0.2680 * * *$ & $\Delta$ Smoking at 16 & -0.0241 \\
Smoking at 18 & $-0.2699 * * *$ & $\Delta$ Smoking at 18 & -0.0541 \\
\hline
\end{tabular}

Note: stars indicate the following significance levels: $* 10 \%, * * 5 \%, * * * 1 \%$. 
$\underline{\text { Table } 5}$

$\underline{\text { Smoking as an instrument: OLS and IV Estimates of the Return to Education for Identical }}$ Twins

(pooled estimates of 5, dependent variable log wages)

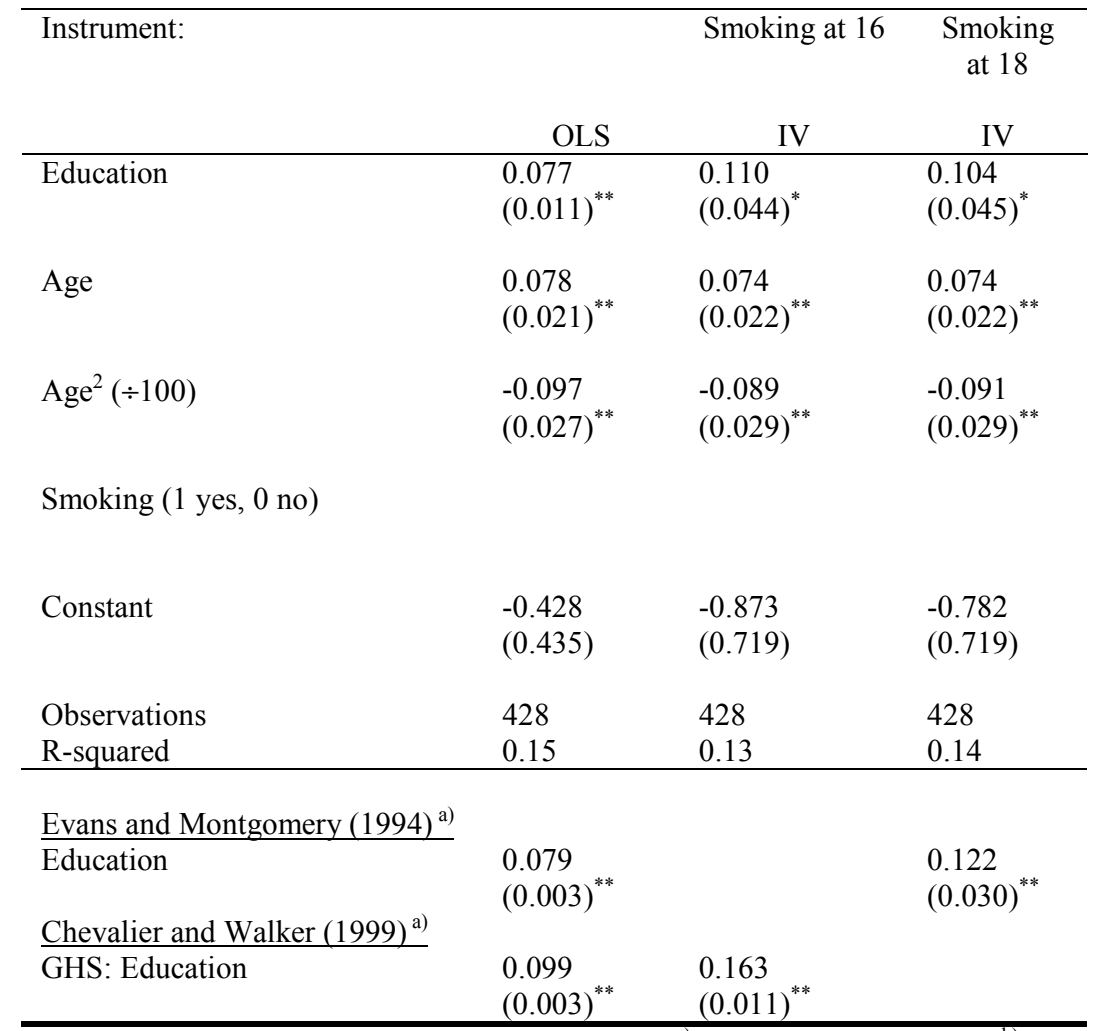

Note: stars indicate the following significance levels: $* 5 \%, * * 1 \%$. ${ }^{\text {a) }}$ Results from Table $10{ }^{\left.{ }^{b}\right)}$ Results from Table 23 (General Household Survey, GHS). The age of smoking is not specified in their paper.. 
Figure 1

Differences in log hourly earnings against differences in schooling (schooling based on highest qualifications)

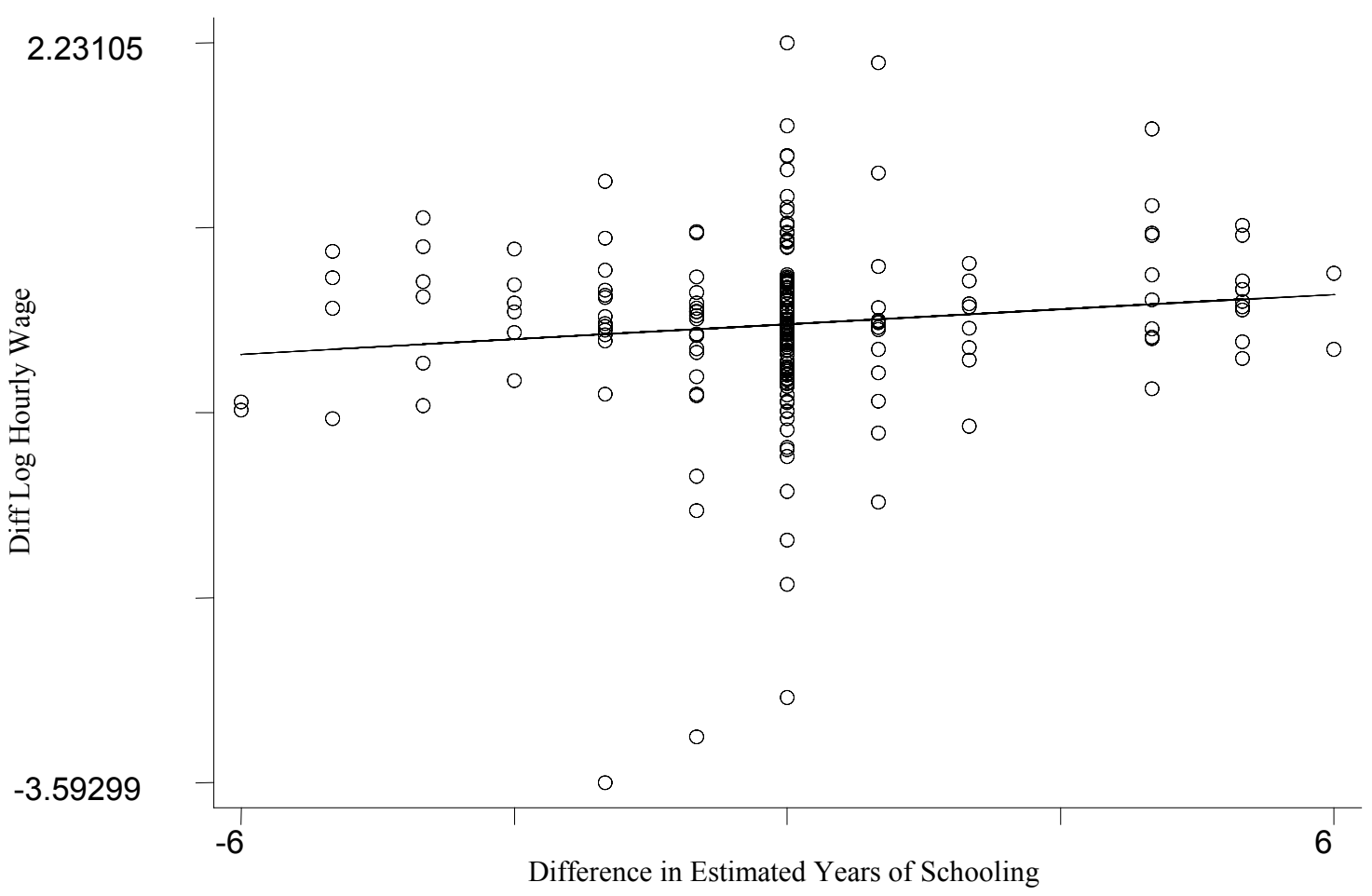




\section{References}

Angrist, J. and Krueger, A., (1991), "Does compulsory School Attendance Affect Schooling and Earnings", Quarterly Journal of Economics, 106, pp. 979-1014

Ashenfelter, O. and Krueger, A., (1994), "Estimating the Returns to Schooling Using a New Sample of Twins", American Economic Review, 84, pp. 1157-1173.

Ashenfelter, O and Rouse, C, (1998), "Income, Schooling and Ability: Evidence from a New Sample of Identical Twins", Quarterly Journal of Economics, Feb 1998, pp. 253-284.

Ashenfelter, O. and Zimmerman, D., (1997), "Estimates of the Returns to Schooling from Sibling Data: Fathers, Sons, and Brothers", Review of Economics and Statistics, 79, pp. 1-9.

Behrman J. and Rosenzweig, M., (1999), "“Ability” Biases in Schooling Returns and Twins: A Test and New Estimates ", Economics of Education Review, 18, pp. 159-167.

Blanchflower, D., and Elias, P., (1999) "Ability, Schooling and Earnings: Are Twins Different?" unpublished manuscript.

Bound J., and Solon, G., (1999), "Double Trouble: On the Value of Twins-Based Estimation of the Return to Schooling", Economics of Education Review, 18, pp. 169-182.

Bryan, E., (1992) "Twins and Higher Multiple Births - A Guide to their Nature and Nurture", London/Melbourne/Auckland: Edward Arnold.

Card, D., (1995), "Using Geographic Variation in College Proximity to Estimate the Return to Schooling", in L. Christofides, E. Grant, and R. Swidinsky, editors, Aspects of Labour Market Behaviour: Essays in Honour of John Vanderkamp, University of Toronto Press, Toronto: pp. 201-222.

Card, D, (1999), "The Causal Effect of Education on Earnings", in O. Ashenfelter and D. Card, editors, Handbook of Labor Economics, Elsevier Science B.V.

Crawford, J. R., I. J. Dearly, J. Starr and L. J. Whalley (2001) "The NART as an index of prior intellectual functioning: a retrospective validity study covering a 66-year interval", Psychological Medicine, 31, 451-458.

Dearden, L., (1998), “Ability, Families, Education and Earnings in the UK”, IFS working paper No. W98/14.

Dearden, L., (1999), "Qualifications and Earnings in Britain: how reliable are conventional OLS estimates of the returns to education?", IFS working paper No. W99/7.

Evans, W. N. and E. Montgomery (1994) "Education and health: Where there's smoke there's an instrument”, NBER working paper \#4949.

Fuchs, V.R. (1986), "Schooling and Health: The Cigarette Connection", Journal of Health Economics, 1, pp 217-30.

Griliches, Z., (1979), "Sibling Models and Data in Economics: Beginnings of a Survey", Journal of Political Economy, 87, pp. S37-S65. 
Hamermesh, D (1999) "The Art of Labormetrics", NBER Working Paper 6927.

Harmon, C., and Walker, I., (1995), "Estimates of the Economic Return to Schooling for the United Kingdom", American Economic Review, 85, pp.1278-1286.

Herrnstein, R., and Murray, C., (1994), The Bell Curve, New York: Free Press.

Isacsson, G. (1999), Essays on the Twins Approach in Empirical Labor Economics, Swedish Institute for Social Research, Stockholm.

Miller, P., Mulvey, C., and Martin, N., (1995), "What do Twins Studies Reveal About the Economic Returns to Education? A Comparison of Australian and U.S. Findings", American Economic Review, 85, pp. 586-599.

Neumark, D., (1999), "Biases in Twin Estimates of the Return to Schooling", Economics of Education Review, 18, pp.143-148.

Rouse, C., (1999), "Further Estimates of the Economic Return to Schooling from a New Sample of Twins", Economics of Education Review, 18, pp.149-157.

Taubman, P., (1976), "Earnings, Education, Genetics, and Environment", Journal of Human Resources, 11, pp. 447-461. 


\section{DATA APPENDIX}

The identification of the twins as identical or fraternal is generated at the Twins Unit using a set of standardised questions. In addition these results are compared, where possible, to DNA data held at the Unit.

If both twins are present in the sample they are recorded as a pair, if only one twin is present they are recorded as a singleton.

Reported Years of Schooling are found by subtracting five years from the age reported for finishing full-time education. This does not account for pre-school or adult education. For example someone who reports that they left school at 17 will have $17-5=12$ reported years of schooling.

Estimated Years of Schooling are based on the highest qualification reported. The qualifications were ranked and assigned the number of years necessary to achieve the qualification as follows (in descending order). In addition the LFS data were matched into our qualifications groups as below.

Twins Groupings Years Allocated

University

Higher Vocational

Teaching

16

Nursing

A-Level

14

Middle Vocational

12

O-Level

Low Vocational

11

\section{LFS Grouping}

\author{
Higher Degree \\ NVQ Level 5 \\ First Degree \\ Other Degree
}

NVQ Level 4

Diploma in Higher Education

HNC/HND, BTEC Higher etc

RSA Higher Diploma

Other Higher Education Below Degree Level

Teaching - Further Education

Teaching - Secondary

Teaching - Primary

Teaching - Level Not Stated

Nursing etc

A-Level or Equivalent

SCE Higher or Equivalent

AS Level or Equivalent

Scottish $6^{\text {th }}$ Year Certificate (CSYS)

NVQ Level 3

GNVQ Advanced

RSA Advanced Diploma

OND/ONC, BTEC/SCOTVEC National

City and Guilds Advanced Craft

O Level, GCSE Grade A-C or Equivalent CSE Below Grade 1, GCSE Below Grade C

Trade Apprenticeship

NVQ Level 2

GNVQ Intermediate

RSA Diploma

City and Guilds Craft

BTEC/SCOTVEC First or General Diploma 
Clerical

Other

No Qualifications
11

11

10
NVQ Level 1

GNVQ/GSVQ Foundation Level

BTEC/SCOTVEC First or General Certificate SCOTVEC Modules

RSA Other

City and Guilds Other

YT/YTP Certificate

Other Qualifications

No Qualifications

Don't Know

Married is a dummy variable equalling 1 for married women and 0 otherwise.

White is a dummy variable equalling 1 for white women and 0 otherwise.

Non-participation is a dummy variable equalling 1 for women reporting "Not working, not actively seeking work" in the questionnaire and 0 otherwise.

Hourly Earnings were calculated as follows for those working:

(1) For those reporting hourly earnings these were taken as given.

(2) For those reporting daily earnings, a working day of eight hours was assumed. Hourly earnings therefore were found to be reported daily earnings multiplied by reported weekly hours divided by eight. This was then all divided by reported weekly hours. This calculation can cause some problems for part-time workers. However, only ten twins in the whole sample and two twins in the sample of working twin pairs reported daily wages.

(3) For those reporting weekly earnings, hourly earnings were found by dividing reported weekly earnings by reported weekly hours.

(4) For those reporting monthly earnings, a working month of four weeks was assumed. Hourly earnings therefore were found to be reported monthly earnings divided by four all divided by reported weekly hours.

(5) For those reporting annual earnings, a working year of fifty-two weeks was assumed (full time staff are generally have paid during vacations). Hourly earnings therefore were found to be reported annual earning divided by fifty two all divided by reported weekly earnings.

Tenure is the years spent in present occupation.

Full-time is a dummy equalling 1 for women reporting "Working in a job, full-time" and 0 otherwise.

Self-employed is a dummy variable equalling 1 for women reporting "Working as self-employed" and 0 otherwise.

Partner's Occupation is an index variable ranking from 1 to 8 with the following categories: plant and machine operatives, sales occupations, personal and protective services, crafts and related occupations, clerical and secretarial occupations, associate professional occupations, professional occupations.

Partner's tenure is partner's years spent in present occupation. 


\section{Q Queen Mary \\ University of London}

This working paper has been produced by the Department of Economics at Queen Mary, University of London

Copyright @ 2002 Dorothe Bonjour, Lyn Cherkas, Jonathan Haskel, Denise Hawkes and Tim Spector. All rights reserved.

\section{Department of Economics}

Queen Mary, University of London

Mile End Road

London E1 4NS

Tel: $+44(0) 2078825096$ or Fax: +44 (0)20 89833580

Email: j.conner@qmul.ac.uk

Website: www.econ.qmul.ac.uk/papers/wp.htm 